\title{
Firmas de acto-acuerdo. Performance estatal en la construcción del "problema de la seguridad" en la provincia de Córdoba
}

\author{
Signatures of act-agreement. State performance in the construction \\ of the "security problem" in the province of Córdoba
}

\author{
Sofía María Vittorelli sofia.vittorelli@gmail.com \\ http://orcid.org/0000-0001-8688-6882 \\ Facultad de Filosofía y Humanidades; \\ Universidad Nacional de Córdoba (Argentina)
}

\section{Resumen}

Este artículo se propone indagar sobre la construcción del "problema de la seguridad" desde dos eventos gubernamentales denominados: firmas de acta acuerdo, desde una perspectiva antropológica. El primero, entre el gobierno provincial de Córdoba, la Policía de la provincia y vecinos auto-convocados en espacios de participación ciudadana, referido a la construcción conjunta de un mapa del delito. El segundo, refiere a la firma de un convenio entre el Municipio de la ciudad de Córdoba y el gobierno provincial en materia de infraestructura y seguridad. A partir de ellos, se buscará examinar el carácter performático de tales eventos -reglados protocolarmente- en la consagración de determinados recursos materiales y simbólicos ligados, en este caso, al control (y definición) del delito. Asimismo, la firma, que certifica y garantiza el compromiso de las partes en una cuestión particular, se alza como el momento culmine que 
permite reflexionar acerca del poder performático que lo escrito representa. El encuentro de las partes firmantes no es un hecho aislado, sino parte de un conjunto integrado por otras acciones conjuntas que refuerzan el sentido performático de la administración pública. Entendiendo al trabajo etnográfico como un saber producido en contextos, propongo etnografiar tales eventos ligados al proceso de formación estatal.

Palabras claves: seguridad ciudadana; performance; actuaciones estatales.

\section{Abstract}

This article examine the construction about the "security problem" as of two governmental events will be denoted: act agreement endorsement. First, between the government of the province de Córdoba, the Police and neighbors self- convened in space of citizen participation. In the second case, analyze the collective agreement amongst the municipality of the city of Córdoba and the province government on infrastructure and security. They use these to review the character performance of them -regulated by protocol- in the consecration of certain material and symbolic resource are linked, in this particular case, to the control (and definition) of crime. Also, the firm, with certificate and provide the engagement of the parts in a particular question, it gives that moment culminate that considered about the power performatico the written its represent. This engagement didn't is an alone event, but part of series of actions have been increase the effects performatico of the public administration. To understand the ethnographic work as knowledge, produce in context, I propose etnograph suck events liked to processes of state formation.

Keywords: citizen security; performance; state intervention.

Las consideraciones a las que arriba este artículo se enmarcan dentro de un trabajo final de Licenciatura en Antropología, que tiene como objetivo indagar en la construcción de un modelo securitario de participación ciudadana (1) en la provincia de Córdoba. En términos generales, mi propuesta intenta examinar las condiciones sociales y políticas de construcción de una agenda gubernamental y pública securitaria en la provincia de Córdoba, donde la participación de los vecinos/as -en la gestión de la seguridad- emerge como un elemento central e innovador. Tal participación ocurre dentro de marcos institucionales establecidos y reconocidos normativamente, que reciben el nombre de Consejos barriales. Estos espacios de participación vecinal formaron parte de un programa gubernamental en materia de seguridad anunciado, y 
seguidamente implementado, durante la campaña política del actual gobernador de la provincia Schiaretti, a finales de 2015. Mi interés de trabajar con este programa y particularmente con uno de los primeros Consejos barriales que se conformó en la ciudad, devino como consecuencia de la intención de examinar la construcción de un "problema social" (Lenoir, 1993) ligado a la seguridad ciudadana, como concepto teórico -pero también con incidencia en el campo político- movilizado por un conjunto de agentes estatales e internacionales relacionados al campo de la gestación de políticas públicas, como por una serie de funcionarios públicos provinciales.

Las escenas que aquí serán presentadas son parte de un conjunto de prácticas gubernamentales que observé a lo largo de mi trabajo de campo, que lejos de quedar circunscrito al análisis del Consejo barrial, de los vecinos/as que en él participaban, o de las actividades que se realizaban; buscó (des)entrarse con respecto a éstos para comprender desde un orden sociológico la continuidad-discontinuidad de determinadas política(s) pública(s), los sentidos y representaciones de la "seguridad" en tanto "problema social". Mediante este movimiento analítico, de des-institucionalocentrismo, Foucault (2006) nos propone el paso hacia el exterior de la institución en la búsqueda de una "tecnología de poder"; al mismo tiempo que nos permite reconstruir toda "una red de alianzas, comunicaciones y puntos de apoyo" (p.141). Este descentramiento implicó entender a los Consejos barriales como instituciones que sólo pueden ser comprendidas si hacemos foco en un orden más general, vinculado a políticas públicas y programas de seguridad ciudadana locales como regionales. Frente a ello me pregunto, ¿Qué tipo de vecinos/ciudadanos se construyen/producen desde estos programas de seguridad ciudadana? ¿Qué sentidos de seguridad-inseguridad construyen estos programas de seguridad ciudadana? ¿Cómo los miembros de dichos espacios institucionales construyen sentidos de seguridad-inseguridad? ¿A quiénes estarían destinados dichos programas? ¿Cómo dichos programas se insertan en lógicas seguritarias más amplias?

Siguiendo la propuesta de Sousa Lima y Castro (2008) debemos analizar estas prácticas gubernamentales de firmas de acta acuerdo como planos, acciones y tecnologías de gobierno formuladas desde las administraciones de los Estados Nacionales. Es frecuente, en la actualidad, que los gobiernos tanto municipales, como provinciales y/o nacionales firmen entre ellos acuerdos de coparticipación en la gestión de un determinado proyecto de infraestructura o se comprometan en la implementación de una política social que ambos consideran importante. Podríamos describir a estos tipos de firma de acta acuerdo como el encuentro político de dos o más agentes sociales $y / 0$ instituciones (estatales $u$ otras) en la búsqueda de acuerdos. 
Además, tal encuentro se ancla en una materialidad específica: puede tratarse de un libro de acta o una carpeta de cartón; en sus páginas se registrarán esos acuerdos. Las firmas que acompañarán al texto validarán y certificarán el compromiso por escrito. El hecho de firmar frente a una audiencia pública imprime, en los acuerdos aquí analizados, determinadas expectativas en el público. Es por ello, que los firmantes se ven en la obligación de decir algo al respecto.

En cada firma de acta acuerdo se construyen relaciones políticas, se establecen jerarquías sociales y se (des)habilitan jurisdicciones entre áreas de gobierno, así como se establecen ciertas relaciones saber-poder (Foucault, 1988) entre gobierno y ciudadanos. Además, en cada acto los gobiernos exhiben una serie de elementos y distinciones simbólicas que refuerzan esas relaciones y jerarquías, me refiero a las prácticas y discursos que, en los eventos aquí examinados, hacen posible la construcción y definición del "problema de la seguridad" en la provincia de Córdoba así como la distribución de ciertos roles entre agentes policiales y vecinos auto-convocados.

Por otro lado, estas prácticas estatales, exhiben un conjunto de convenciones ritualizadas interesantes para analizar al estado como "performance". En estos actos se producen conjuntamente una idea de Estado-Nación y un "hábitus nacional" (Elias, 2016) que liga a los miembros de esas comunidades políticas y territoriales entre sí, y les permite reconocerse como "compatriotas" (Blázquez, 2014: 18). La celebración de estas convenciones ritualizadas acontecen en edificios gubernamentales, especialmente en auditorios extensos, son abiertos al público y a los medios de comunicación. Las conductas de los diferentes sujetos que ocuparán el escenario y el orden del espacio se encuentran establecidos de antemano por protocolos formales que procuran enfocar e intensificar la atención sobre las personas, objetos y sucesos asociados a la idea del estado y Nación. En este caso, al tratarse de firmas de acta acuerdo en el marco de la "seguridad", el estado (y sus acciones) es realizado performativamente en esas conductas rituales. Conductas que asimismo refuerzan la centralidad que el estado ocupa en la definición de las políticas públicas securitarias. Finalmente, al momento de examinar estos acuerdos debemos tener en cuenta que se tratan de acuerdos generados en el marco de determinadas políticas públicas, y al observar los modos en que son objetivadas y utilizadas esas políticas podremos comprender algunos de los principios más profundos que estructuran nuestra sociedad.

En primer lugar como se señaló en el resumen, analizaré la firma de un acto acuerdo en la Jefatura de la Policía de Córdoba, entre Gobierno de la Provincia, Policía de Córdoba y representantes de Juntas Vecinales de Participación Ciudadana para la conformación de un 
mapa del delito. En segundo lugar, también una firma de acto acuerdo entre Gobierno de la Provincia y Municipalidad de la ciudad de Córdoba, para la cogestión de infraestructura como parte del Plan de Seguridad Integral de Seguridad Ciudadana y Prevención al Delito. A continuación, reconstruiré desde mis notas de campo, ambas escenas gubernamentales (2).

\section{La construcción de un mapa del delito. Abril 2014}

La invitación a asistir al evento en la Jefatura de la Policía de Córdoba me había llegado por mensaje privado de Facebook y por Rubén (3), un vecino que conocí al comienzo de mi trabajo de campo en abril de 2014. En aquél entonces, Rubén junto a otros vecinos/as autoconvocados habían decidido conformar una Junta de Participación Ciudadana. Mencionaré aquí que estas Juntas, luego de la asunción del gobernador de Schiaretti a finales de 2015, se disolvieron y en su lugar se conformaron Consejos barriales. La particularidad que adquieren éstos último en el marco de un nuevo programa securitario es que fueron conformados a partir de una intervención gubernamental en determinados barrios vulnerables (la mayoría periféricos de la ciudad) y no producto de vecinos auto-convocados o que "espontáneamente" se habían organizado para hacer algo por el barrio. Si bien el plan es jurisdiccionalmente provincial, hasta la actualidad solo se han inaugurado Consejos en los límites de la ciudad de Córdoba. A su vez, otras de las particularidades que adquieren estos Consejos barriales, es que están conformado no por un solo barrio, sino por varios (más de uno). Es decir, cada Consejo barrial agrupa diversos y aledaños barrios de la ciudad de Córdoba, y no solo uno como las anteriores Juntas. Este agrupamiento deviene de estudios estadísticos que la provincia realizó, específicamente son producto del entrecruzamiento de tres variables: índice de vulnerabilidad social y económica, porcentaje delictual e índices de empleo formal y no formal. Mi trabajo de campo continuó esta serie (y otros) acontecimientos y cambios institucionales vinculados a las políticas securitarias de la provincia prestando atención al lugar que la ciudadanía fue ocupando, disputando en ellas.

La firma del acta acuerdo entre funcionarios provinciales, Jefes de la Policía y vecinos autoconvocados ocurrió en el anfiteatro de la Jefatura. A partir de una descripción densa (Geertz, 1986) examinaré lo acontecido durante ese día, con el objetivo de desentrañar el conjunto de sentidos, sujetos, representaciones, así como de sensaciones, impresiones, emociones que moviliza el "problema de la seguridad", en la Córdoba contemporánea. La firma de este convenio aconteció meses después del denominado auto-acuartelamiento policial de diciembre 
de 2013. Como producto del acuartelamiento, se produjeron una serie de hechos de violencia, cuya principal resultado fue la muerte de un joven motociclista, producto de una fuerte golpiza en manos de vecinos/as. Asimismo, a lo largo de esa jornada se registraron saqueos a supermercados y robos a comercios de la ciudad (4). La poca distancia entre estos hechos y la firma del acta acuerdo no es casual, sino producto de un objetivo gubernamental de reparar el daño social, restablecer los vínculos entre la policía y los ciudadanos; y de perpetuar el control de ciertas territorialidades y sujetos, así como de conservar-mantener ciertas posiciones y relaciones a meses, en ese momento, de las elecciones provinciales.

Todo estaba preparado para la ocasión. En el escenario, una pequeña mesa de madera oscura y cuatro sillas a su alrededor. Hacia la izquierda del cuadro, la bandera Argentina y la bandera de Córdoba reposaban en sus respectivos pedestales, y a su derecha un proyector en cuya imagen sobresalía: mapa geo referenciado del delito. Enfrente, varias hileras de butacas que de a poco el público fue ocupando. En los laterales, varios medios locales posicionaron sus cámaras en ángulo hacia el escenario; el acto que estaríamos por presenciar ameritaba la presencia de los medios. Las butacas se fueron ocupando de acuerdo a un orden que hasta el momento no había reparado. Las primeras tres hileras fueron ocupadas por la fuerza policial: la primera, a su vez, por los altos mandos y jefes, quienes vestían trajes azul oscuro y poseían una mayor cantidad de insignias en el hombro; la segunda por oficiales de rango medio, y la tercera por otros suboficiales de camisa blanca. Así, el espacio físico en el que se situaron los agentes policiales daba cuenta de un "espacio social" (Bourdieu, 1999) que se definió por la exclusión mutua de las posiciones y por la distancia relacional que existía entre unos y otros. Sin embargo, las primeras filas también fueron ocupadas por algunos de los funcionarios invitados al evento, destacándose por su vestimenta de saco y corbata. Con la intensión de mantener los arreglos sociales previos, decidí sentarme al final del auditorio, ya que el público "en general", en los actos gubernamentales, ocupa las últimas filas.

Las butacas del auditorio fueron ocupadas en su totalidad. Otras personas debieron quedarse paradas en los laterales del auditorio. Alrededor de 150 personas ocupábamos el salón, eran más varones que mujeres, cuyas edades rondaban entre los 40 y 60 años. Minutos previos al acto y en el hall central de la Jefatura, el gobierno de la provincia y el área de participación ciudadana agasajaron a los invitados/as con un banquete de alimentos y bebidas. Esta celebración previa relajó el clima tenso y expectante que tenían los vecinos/as. La degustación de los alimentos medió las conversaciones entre vecinos/as y funcionarios, así como habilitó posiciones que permitieron ligar al gobierno y a los funcionarios presentes a ciertas 
disposiciones y compromisos, vinculadas, en este caso, con el "problema de la seguridad" y una escucha atenta de los vecinos/as. Volveré a este punto más adelante.

Un orador se acercó al pupitre y al micrófono, y reproduciendo el orden espacial nos dio la bienvenida. En primer lugar, saludó y agradeció la presencia de las autoridades de gobierno entre las que se encontraba el Secretario de Participación Ciudadana Diego Hak, luego al Comisario General, Comisario Mayor, y demás miembros de la Fuerza Policial; empresarios de la Cámara de Almaceneros Córdoba, miembros de las Juntas de Participación Ciudadana, vecinos auto-convocados, medios locales y público en general. Seguidamente y de forma resumida comentó la intensión del evento. Se trataba de una firma de convenio de coparticipación entre la Policía Provincial de Córdoba, vecinos de Córdoba y dos unidades de referencia: Cámara de Comercio y el Centro de Almaceneros. Tal convenio incluía la elaboración conjunta de un mapa geo-referenciado de la ciudad de Córdoba, a través de la herramienta Google Maps.

Posteriormente el orador invitó al Jefe de Policía, al Secretario de Participación Ciudadana, al representante de la Cámara de Comercio y a Rubén, coordinador de la Junta de Participación Ciudadana del barrio Los Molinos (en calidad de representante vecinal), a subir al escenario. Los cuatro subieron y fueron ocupando las sillas dispuestas, procurando mantener el orden establecido, (de der a izq.): Jefe de Policía, Secretario, representante del comercio y Rubén. Luego, un secretario de traje y corbata subió al escenario e hizo entrega de una carpeta de papel (marrón) que en su interior contenía el acta acuerdo. El orador, respetando el mismo orden, anunció al público la firma de cada uno de los representantes, quienes en el momento en que iban siendo nombrados firmaban. El público acompañó las firmas con aplausos y gritos de aliento: -ibravo, bravo! El último en firmar, Rubén, levantó la carpeta mostrando al público el acta y las firmas; le siguieron aplausos y más aplausos. Acompañé al público en los aplausos. En lo siguiente, los firmantes tomaron la palabra y desde el escenario se expresaron a favor del acuerdo.

Los puntos y lugares señalados que veíamos en el mapa, eran producto del cruce de datos entre las entidades firmantes. Estos puntos específicos hacían referencia a lugares peligrosos, violentos y atemorizantes, que debían ser tenidos en cuenta en los recorridos y controles que realizaba la Policía. El Secretario Hak señaló: estos puntos son parte del conocimiento acabado de la realidad, producto de experiencias concretas en el territorio, por ustedes, los vecinos. Asimismo, agregó que la seguridad no era la mera presencia policial en las calles, sino producto de una construcción de todos; y que el acercamiento logrado para la elaboración del presente plan era de destacar, ya que la nueva fuerza se mostraba con otra actitud. El 
comisario en jefe tomó la palabra y resaltó la nueva energía que tenía la policía en su interior, por ello, los hechos acontecidos durante el mes de diciembre debían ser olvidados, ya con él se fundaba una nueva policía proactiva y del consenso. En otros términos, resaltó la necesidad de reformar la policía mediante nuevas medidas en contra del delito que se tradujera en acciones preventivas, pero también persecutorias. Por último, resaltó la importancia del uso de datos cuantitativos como encuestas de victimización y la participación vecinal en la prevención delictual.

En particular, la información entregada por los vecinos/as y por empresarios en la construcción de dicho mapa del delito, además de fijar puntos en el territorio, también establecía frecuencias temporales que dependía de esa espacialidad. Los controles vehiculares -específicamente a motos- debían ser reforzados ya que algunos ciudadanos harían mal uso de estas, sea para delinquir o dañar a otras personas. El comisario señaló que el $80 \%$ de los robos los cometen motochorros, y que era bien sabido el lugar donde se escondían estos. Por último, agregó que si bien su profesión era ingrata y estaba llena de sinsabores: nos gusta, hoy la policía es proactiva, se propone a actuar antes del hecho. Seguidamente, el representante de la Cámara de Comercio reflexionó sobre lo acontecido en diciembre: no hay lamentos ni reproches, es hora de mirar hacia adelante. Brevemente, comentó que la Cámara obraba por el bien social; los datos aportados en la construcción del mapa, fueron recolectados previamente de comerciantes y pequeños almaceneros de la ciudad, quienes preocupados por la "ola" de inseguridad cerraban sus comercios a las 19 hs.

Los resultados presentados en esta instancia, no eran definitivos, se trataba más bien de una etapa inicial en la construcción de un mapa del delito más extenso. Los datos faltantes serían completados por los aportes de otras Juntas de Participación Ciudadana que no habían participado de esta instancia, así como debía ser reactualizado, en vistas a que los modos de delinquir se renovaban, según el comisario. Por último, Rubén tomó la palabra y agradeció la presencia de los vecinos, que trato de amigos. Resaltó que su participación en el plano de la seguridad era muy importante, ya que era necesario trabajar codo a codo en conjunto con la fuerza policial. Ustedes son buenos vecinos. Es por eso que le preparamos semejante bienvenida, señaló. Las relaciones que él había gestionado a lo largo de los años con el gobierno, desde 2008 y como producto de la institucionalización del espacio que coordinaba, habían encontrado un reconocimiento público y político que lo llenaron de orgullo. Al levantar y mostrar el acta hacia el público, Rubén, consagró el acuerdo hacia el público y hacia los medios. Tras su intervención, el orador nos agradeció la participación y dio por finalizado la firma del acto acuerdo. 
De a poco la sala se fue vaciando, algunos periodistas, con micrófono en mano, se acercaron a las primeras filas; algunas de las cámaras se volvieron a encender para captar ese último testimonio. Esperé a Rubén en unos de los costados del escenario. Mientras lo esperaba, una señora se acercó y me entregó varios folletos, me dijo con una sonrisa: llévalos a tu barrio, a tu edificio, pégalos en los comercios cercanos. El folleto formaba parte de una campaña preventiva de seguridad Llame y denuncie. Córdoba contra el delito implementada en 2013, por el Ministerio de Seguridad de Córdoba y la Policía de la Provincia de Córdoba. Lo más resaltado en el folleto era un 0810-DENU, una línea disponible las 24 hs. y por debajo del 0810 el siguiente eslogan: el arma del ciudadano. A la izquierda del folleto una silueta negra de una mujer sosteniendo el tubo de un teléfono fijo. Al reverso, figuraban datos sobre la campaña, objetivos, alcances; en negrita, mayúscula y subrayado la palabra anonimato. En términos generales, la campaña buscaba concientizar al vecino común y alentarlo en la denuncia de hechos criminales (específicamente relacionados con el narcotráfico) preservando el anonimato como método, para conjurar el temor que normalmente genera la exposición de hechos delictivos.

De salida, saludo a Rubén, quien me presenta a nuevos miembros de la Junta de su barrio. Intercambiamos algunas palabras, al mismo tiempo que nos fuimos retirando de la Jefatura. Me despedí de ellos, y de salida me encontré, enfrente de la entrada/salida principal de la jefatura, con una manifestación de motoqueros (5), que corta la cuadra. Crucé la hilera de sub-oficiales, ubicados entre el pasillo de ingreso y las escalinatas de cemento, y me dirigí hacia la parada del colectivo. Entre el humo, producto de las aceleradas constantes, disipé carteles en reclamo por la reglamentación de la ley anti-motos (6). Divisé otro cartel entre la multitud: las personas no se patentan. Las bocinas y aceleradas me ensordecieron. En su mayoría los manifestantes eran jóvenes, varones y algunas mujeres; observé una diversidad de motos de diferentes marcas, cilindrada, colores.

Retomando los ejes centrales que propongo trabajar en este artículo me pregunto: ¿Cuáles son los acontecimientos que ameritan una puesta en escena pública y una práctica política de este tipo? ¿Cómo se gestionan y negocian los múltiples intereses que confluyen en estos actos gubernamentales? ¿Qué sucede cuando ciertos reclamos de seguridad ciudadana se cruzan o "topan" con reclamos viales y vitales? Entre el acto gubernamental, el folleto de prevención y la manifestación motoquera podemos observar cómo la idea-de-estado (Abrams, 1977) se reinventa y, en este caso, cómo el estado provincial gestiona su legitimidad al momento de ejercer el control (y definición) de determinadas problemáticas. El "problema de la seguridad" es redefinido en cada escena dependiendo de las intenciones de los sujetos, de los objetos- 
sujetos en discusión, así como de los métodos y técnicas que estos sujetos proponen para dar respuestas a tal problemática. La vinculación directa que el Comisario realiza entre los conductores de motocicletas y la delincuencia, así como entre motos y hurtos, inscribe al problema securitario en la persecución de determinados delitos callejeros -entre ellos el narcomenudeo- y hacia la propiedad; y deja por fuera otro tipos de delitos y agravios (evasión fiscal, delitos financieros, entre otros). Asimismo, el lugar central que, en este acto, el gobierno le otorga al dato vecinal es diferencial a la posición de negociación que mantienen con los motoqueros. Quiénes, ocupando el espacio público: la calle -territorio que a su vez el mapa busca controlar- se mostraron en contra de los requisitos de identificación y circulación que el gobierno, en pos de una política securitaria, buscaba implementar. Las implicancias sociales y simbólicas de los nuevos requisitos, manifestadas por los jóvenes motoqueros, como circular con el número de patente en el casco y con chaleco fosforescente transgredían, a su vez, cuestiones estéticas e identitarias. Finalmente, no deja de llamar la atención, el hecho de que la mayoría de los motoqueros eran jóvenes y varones, y la asociación que ambas cuestiones representan y significan en el contexto de políticas persecutorias a estos grupos sociales.

Por otro lado, puede rastrearse en las palabras del secretario como en el contenido del folleto cierta narrativa de la "seguridad" como fenómeno integral que requiere de la participación de todos en el diseño y gestión de iniciativas más "eficientes". Para ello, se busca involucrar a la ciudadanía en acciones que favorezcan la prevención (situacional) del delito y en la denuncia anónima de situaciones sospechosas. Así, en el plano de lo discursivo, la participación ciudadana es posicionada por el gobierno como un elemento importante en la gestión de esa agenda, pero en el plano de la práctica tal centralidad se vuelve subsidiaria a las competencias de otras agencias y agendas estatales, principalmente de la Policía y de los gobernantes de turno. En la intensión de confeccionar un mapa del delito puede observarse esto último. La idea fue exclusivamente gestada e impulsada por el Ministerio de Gobierno y principalmente por la Policía de Córdoba. A su vez, estos datos serían utilizados solamente por éstas instituciones estatales. Entonces me pregunto: ¿mapa del delito para qué y para quienes? ¿Cuáles serían las implicancias sociales involucradas en la publicación y uso de esos datos?

Desde este lugar subsidiario, la participación de los vecinos/as es construida desde el lugar de la gestión. De la gestión de territorialidades y emociones, y no como una actividad política, aunque debemos resaltar el hecho de que es a través de la gestión de sus problemáticas barriales que los vecinos/as modifican su realidad y consiguen respuestas gubernamentales. $\mathrm{Si}$ bien la gestión vecinal es definida por los vecinos/as con los que trabajé como una alternativa a la actividad política (mal vista, además cuando es partidaria) de los funcionarios, obtiene en los 
contextos en los que se produce cierta inferencia política: algunas de las cuestiones que los vecinos/as reclaman obtienen respuestas. Aunque, como veremos más adelante, tales gestiones encontrarán límites en una compleja tensión entre dos definiciones del problema securitario. Por último, al observar estas espacialidades y temporalidades podemos señalar que no deberían ser pensados como datos objetivos de una "realidad insegura", sino puntos de referencia que emergen en la conjunción de emociones y sentimientos vinculados al problema securitario, lo que Kessler (2014) denomina el "sentimiento de la inseguridad".

\section{La participación municipal en el plan provincial. Noviembre 2016}

En esta oportunidad, la firma del acto acuerdo estaba prevista a realizarse en el salón principal del Centro Cívico, anteriormente conocida como Casa de Gobierno de la provincia. La convocatoria pública circuló por las redes sociales y varios medios locales reprodujeron la invitación oficial. Algunos de ellos hicieron hincapié en el carácter excepcional de la firma acuerdo, ya que sólo en muy pocas oportunidades municipio y provincia habían consolidado convenios en conjunto. Esto se debía principalmente, según una de las periodistas locales, a la diferencia política entre unos y otros (el municipio de la capital cordobesa está representado por la UCR y la provincia por Unión Por Córdoba, un partido tradicionalmente peronista). Por otro lado, el hecho de que la provincia había invitado al municipio a colaborar en el desarrollo e implementación del nuevo Plan de Seguridad Integral (2015), y a participar activamente en los espacios de participación ciudadana, reforzaba este carácter peculiar.

El anfiteatro estaba lleno, colmado multitudinariamente. No había ni una butaca vacía, hacia los costados, atiborrado de gente. Nuevamente, el escenario en el fondo y en él una mesa donde se firmaría el acuerdo, a su costado un atril con micrófono. Hacia la derecha, un conjunto de sillones formaban un descontracturado living. A la izquierda de la mesa la Bandera Argentina y la Bandera de la provincia de Córdoba presidían el acto. De fondo, una pantalla de $5 \mathrm{mts}$. por 5 mts. aproximadamente donde serán proyectadas una serie de imágenes y consignas. La luz por el momento permaneció tenue, un asesor dejó copas y botellas de agua sobre la mesa. El bullicio era intenso, el público se mostraba impaciente y expectante, yo también lo estaba; decidí buscar un lugar hacia el final del anfiteatro. Medios locales y fotógrafos ocupaban el espacio entre el escenario y las primeras butacas, desde allí capturaron los movimientos de la audiencia y del escenario. 
Al igual que en otras oportunidades, un orador se acercó al atril principal, pidió silencio y anunció que en la brevedad comenzaría el acto. Un grupo de funcionarios ocupó las sillas y otro, los sillones. Los funcionarios saludaban al público agitando sus manos, sonriendo al público. Nuevamente el orador se acercó al atril, nos dio la bienvenida y presentó a las autoridades: El Señor Gobernador de la provincia, Juan Schiaretti; el Intendente de la ciudad, Ramón Mestre; Ministro de gobierno y seguridad, Masse; miembros del gabinete provincial, presidente provisorio del poder legislativo, Doctor González; el Señor asesor de urbanismo social del Ministerio de Gobierno, Gustavo Restrepo; el Señor Jefe de la Policía de la provincia de Córdoba, Comisario general Gustavo Vélez; el Señor Secretario de Seguridad de la provincia de Córdoba, Diego Hak. La señora Secretaria de Equidad y promoción del empleo, Alejandra Vigo. El señor Secretario de Gobierno Municipal, Javier Vicellares. Legisladores y demás autoridades provinciales y municipales. Consejos barriales, queridos vecinos...

Para dar comienzo al acto, se procedió con la firma del denominado acuerdo complementario para el avance y fortalecimiento del plan integral de seguridad ciudadana y prevención del delito entre gobierno de la provincia de Córdoba y el gobierno de la ciudad de Córdoba. El acuerdo establecía la cogestión en obras de infraestructura y seguridad en el marco del Plan Integral de Seguridad Ciudadana y Prevención al delito Córdoba se encuentra que venía implementando, desde hace un par de meses, la provincia. El orador fue anunciando las subsiguientes firmas, en representación de la provincia firmó el Ministro de gobierno y seguridad, y el intendente Ramón Mestre, por el Municipio. Por último, el gobernador firmó rubricando el acuerdo. Entre firma y firma el público acompañó con aplausos, alentando agitadamente el momento y demostrando interés por ello.

A continuación, el asesor de gobierno y arquitecto colombiano Restrepo tomó la palabra. En su presentación refirió a los puntos centrales del Plan Integral, como de los avances y proyectos que hasta la fecha se venían concretando. Asimismo, recuperó una serie de iniciativas llevadas a cabo en la ciudad de Medellín (Colombia), que serían repensadas para el caso cordobés desde las propias problemáticas locales, con una proyección a cuatro años. Medellín representaba aquello a lo que hoy Córdoba debía aspirar, en sus términos: una ciudad segura y con una cultura ciudadana. El proyecto urbano implementado en una de las ciudades más conflictivas de Colombia años atrás y de la mano de este arquitecto, había rendido sus frutos y, en la actualidad, Medellín mostraba cambios significativos en los índices de violencia. Los cambios físicos, acompañados por ayudas económicas y sociales, repercutieron directamente en las tasas delictivas, mejorando, según el arquitecto la calidad de vida de los ciudadanos. 
Este esquema de entendimiento se profundizó a lo largo de la presentación, y de alguna forma operó sedimentando un modo de abordar los problemas securitarios.

Una serie de diapositivas fueron proyectadas y compartidas a la audiencia. A través de ellas, el arquitecto fue relatando las transformaciones más significativas a través de un juego de fotografías que reflejaban un "antes" y un "después". Las propuestas acordadas con la provincia, reflejadas en el Plan Integral, involucraban la creación de rutas seguras, parques divertidos, demos barriales, y casas del futuro en territorios vulnerables. El arquitecto señaló que para el desarrollo de los proyectos era necesario contar con datos sobre las realidades barriales, datos que el equipo técnico -del cual era parte- recuperaría de la Policía y de un mapa construido por el Observatorio de Convivencia y Seguridad Ciudadana de la provincia.

El mapa que nos mostró a continuación dividía a la ciudad en tres colores: rojo, amarillo y verde. Esta forma de cartografiar la ciudad, producto de la aplicación de la técnica del semáforo y un sistema de cuadrantes (7), diferenciaba barrios y zonas de la ciudad. Los colores asimismo inscriben esas zonas dentro de un esquema jerarquizado de acción gubernamental: lo urgente era lo rojo y demarcaba barrios socialmente y económicamente vulnerables; los amarillos, barrios que, en términos del Restrepo, estarían en alerta; y los verdes, zonas de la ciudad que no necesitan intervención del estado. Paralelamente, este esquema de clasificación, sería utilizado por los vecinos/as para marcar y definir sus problemáticas en talleres que el equipo técnico organizaría. De esta forma, los puntos rojos hablan donde los lugares están calientes, son más difíciles, los amarillos los que se están deteriorando y los verdes los que las familias encuentran como positivos, señaló Restrepo.

Los proyectos mencionados a lo largo de la introducción por el arquitecto, fueron presentados como proyectos "macros" y "generales" a través de los cuáles se sedimentarían una serie de trasformaciones sociales. En esta línea, los cambios físicos harían posible la conquista y desarrollo de ciertas actitudes y/o comportamientos relacionados con una actitud ciudadana. Por ejemplo, en el caso de la construcción de rutas seguras, esto es un tramo del territorio compartido por los barrios que conforman el cuadrante, donde se instalarán luminarias led, se repararan veredas y asfalto, se construirán cordones cunetas y se colocaran árboles. Al introducir tales modificaciones físicas, las personas podrán encontrarse, caminar y sentirse seguras, todo ello señala Restrepo, en favor de mejorar la calidad de vida. La expectativa gubernamental de introducir modificaciones sociales y determinados comportamientos ciudadanos responsables a través de cambios físicos, atraviesa todo el Plan Integral. Otro de los ejemplos señalados, fue la construcción de plazas y parques en lotes fiscales (provinciales 
o municipales) para que las familias puedan llevar a sus hijos, y generar una cultura del hacer, una cultura de la educación.

Los destinatarios de estos proyectos serán los vecinos/as de estos barrios, pero también, la intención de Restrepo, es generar ideas con los jóvenes de estos barrios vulnerables. Un sector social que para el arquitecto se encuentra desatendido por el estado. Los demos barriales estarán pensados para trabajar con jóvenes entusiastas, desarrollando actividades que los vinculen de manera positiva, a una vida positiva en profundidad. Todo ello a fines de fundar una cultura ciudadana donde las cosas no se obtienen como regalos sino que son producto del trabajo. En pocas palabras, menciona el proyecto de salas cunas y el acompañamiento estatal que las mamás jóvenes han logrado. Por último, señala la condición interdisciplinar del Plan Integral que se manifiesta en una labor interministerial de gobierno, logrando así un trabajo continuado y profundo de las situaciones de vulnerabilidad.

Luego de esta extensa presentación, el Intendente Mestre fue invitado a decir unas palabras. La audiencia aplaudió con mucha intensidad, a diferencia quizás de los aplausos dedicados, en la presentación, al Gobernador de Córdoba. Repitiendo el orden consignado por el orador, agradeció la presencia y la invitación a los funcionarios, y al público en general. Su intervención refirió a la importancia de lograr un trabajo en conjunto entre municipio y provincia en materia de "seguridad" como producto de dos pasiones que se cruzan: la del encuentro y la de las buenas costumbres. En el primer caso, destacó la buena voluntad del gobernador y su equipo en sumarse al trabajo con los barrios, luego de varios años de relaciones truncadas con el gobierno nacional y la imposibilidad de concretar económicamente algunos proyectos (8). En el segundo caso, destacó la posibilidad del encuentro que permite llevar adelante con buenas costumbres la resolución de los conflictos y de los problemas. A través de tales consideraciones, el intendente buscó interpelar al público con un mensaje alentador sobre el acuerdo firmado, y dejar en claro -en esa ocasión- su modo de entender la práctica política en tanto diálogo entre diferentes gobiernos y/o partidos políticos

El último en tomar la palabra, y a modo de cierre, fue el Gobernador de la provincia. Se refirió a la audiencia en términos de amigos y amigas, con un tono cálido y subido en intensidad por momentos (9). Luego, se refirió al convenio como la mayor suma invertida entre provincia y municipio, un total de 815.000 .000 pesos destinados a 175 barrios de la ciudad y como consecuente a 434.000 ciudadanos/as. El carácter significativo de tales obras, más allá del monto en dinero, recaía en que tales obras y proyectos eran propuestas diseñadas por los mismos vecinos/as nucleados en los Consejos barriales. Tales obras, se volvían centrales, según el gobernador, en la lucha contra el narcotráfico y la delincuencia provincial pero también 
en el plano nacional. Así, este proyecto continúa la propuesta del gobierno nacional de sedimentar tales actuaciones en políticas de estado y no en simples programas gubernamentales, que a la larga se desmoronan.

Por otro lado, el gobernador se refirió a la problemática del narcotráfico y de la inseguridad como hijas de la exclusión social. En estos términos, concluyó que las acciones estatales en materia de "seguridad" deberían atender a los sectores más vulnerables de la ciudad, las zonas urbano-marginales, las mujeres embarazadas y los niños/as. Paralelamente, y casi en otro extremo ubica a otra serie de acciones gubernamentales destinadas a garantizar la paz y la tranquilidad de los vecinos/as. En esta línea, destacó la proyección de obras de infraestructura y la presencia en el terreno estatal que estaría garantizada por la fuerza policial como hechos que repercuten directamente en el orden social. Si bien la propuesta gubernamental apunta a que ambas acciones confluyan, se construye con un mayor énfasis la segunda intervención. Asimismo, se refuerzan determinados sentidos e imágenes sobre la "inseguridad" y el rol que la Policía debería ocupar. Esto puede ser observado en las siguientes palabras del gobernador:

No nos vamos a dejar intimidar, no nos vamos a dejar quitar la tranquilidad, no nos van a obligar permanentemente a cerrar la puerta de la casa a las 8 de la noche, no nos van a quitar los sueños de un mundo mejor. Córdoba no se rinde carajo, los narcotraficantes no se van a ser dueños de los barrios de esta querida ciudad de Córdoba, vamos a darle la batalla y se la vamos a ganar.

El uso de términos beligerantes, así como el uso de un tono de voz con una intensidad más acentuada buscando la atención de la audiencia, fue utilizado por el gobernador hacia el final de su intervención. Su argumento continúo: porque no queremos más que no se pueda salir a la calle, no queremos que las drogas se lleven a nuestros niños de las barriadas más humildes, no vamos a dejar que la droga nos maneje las barriadas más humildes, y entramos para quedarnos y para pelearle palma a palma. Desde este lugar convocó a la ciudadanía a participar e involucrarse en el proyecto de "seguridad": vamos a ganar esta pelea porque es la pelea del pueblo que quiere vivir en paz y en felicidad. El público se puso de pie y acompañó con calurosos aplausos las últimas palabras del gobernador. El locutor se acercó al atril y dio por finalizado el acto.

En el hall de entrada y salida al anfiteatro me crucé con Rubén y vecinos/as del Consejo barrial. Me transmitieron que estaban conformes con las palabras del gobernador, pero que de los dichos a los hechos había un largo trecho, y que muchas de las cuestiones dichas, habían sido anunciadas años atrás. Unas de las vecinas me dijo: espero que esta vez cumplan y no seamos rehenes de la burocracia. Tras estas palabras rehenes de la burocracia, la vecina 
colocó en escena una situación experimentada cotidianamente y asiduamente demandada por los vecinos/as dentro de estos espacios de participación ciudadana. En la mayoría de las reuniones del Consejo donde realicé trabajo de campo observé que, si bien el "problema de la seguridad" era construido por estos vecinos/as bajo demandas de mayor presencia y controles policiales, aparecía relacionado a ciertos reclamos barriales tales como obras de asfalto, poda de árboles, recolección de basura, entre otros. Esta particularidad trajo discusiones al interior del Consejo y entre la relación vecinos-funcionarios. En principio, estas discusiones se suscitaron como consecuencia de la demora del gobierno en solucionar estos reclamos por la falta de recursos económicos, del contraste entre los tiempos burocráticos-políticos -como señala la vecina- y los tiempos vecinales, así como de la falta de comunicación entre funcionarios y dependencias estatales vinculadas al Plan Integral. Sin embargo, estas cuestiones evidenciaban, más bien, una compleja tensión entre dos definiciones del "problema de la seguridad". Por un lado, definiciones vecinales que construyen el problema securitario desde la falla de los servicios públicos y desde ciertas carencias infraestructurales. Por otro lado, intervenciones gubernamentales que se definen desde una agenda de la prevención especialmente relacionada con el narcotráfico; y a través de la implementación de un conjunto de modificaciones urbanas, procurando que éstas transformen la cultura ciudadana.

En el convenio firmado por el municipio y la provincia se hace aún más evidente. La intervención gubernamental del arquitecto jerarquiza las cuestiones físicas, pero éstas parecieran quedar circunscritas a modificaciones del paisaje y de los espacios verdes. Por su parte, el gobernador también refuerza estos sentidos securitarios al centrar su discurso en el paradigma de la prevención y explicitar firmemente que la atención estará puesta en la problemática del narcotráfico. Sentidos que, en correlación con las variables cuantitativas propuestas para cartografiar la ciudad, construyen representaciones sobre esos territorios y por ende de la(s) violencia(s). En el mapa presentado por Restrepo, la mayoría de los territorios señalados con el color rojo se ubicaban en las periferias de la ciudad; zonas a las que, por dinámicas centralizadas de la administración estatal (en este caso, del municipio), se destinan pocos recursos.

Por otro lado, resulta interesante cómo el proyecto de Medellín ejemplifica el modelo de ciudad segura a la que Córdoba debería aspirar. Me gustaría dejar aquí planteado en carácter de interrogantes, pero que no serán respondido, de qué modo circulan y viajan determinadas fórmulas o recetas para disminuir/erradicar la "inseguridad" y la violencia -muchas de ellas certificadas por organismos internacionales como Banco Mundial o UNICEF-, ¿de qué forma son incorporadas en los programas locales? y ¿qué tipo de vínculos construye, legitima? En 
relación a este punto me pregunto por estos "modelos exitosos" o "líneas internacionales" que estos planes de seguridad locales adoptan, como por la intervención de técnicos internacionales.

\section{La gestión de la (in)seguridad en la producción performativa del estado}

El objetivo de recuperar estas actuaciones gubernamentales como performance estatales no fue sino con la intención de interrogar al estado en su carácter performativo. Es a partir de estas prácticas políticas que el estado se constituye, fomentando el vínculo entre diferentes agentes -Policía, vecinos, comerciantes y especialistas- y ordenando relaciones, de modo tal que se reproduzca su lugar central en la definición del modelo securitario. Estos actos forman parte de una agenda gubernamental que se actualiza y organiza en diferentes ocasiones del año, de acuerdo con los intereses dominantes. Así, la primera firma de acto acuerdo y la entrega del mapa geo-referenciado fueron experimentadas como la actualización del contrato social, endeble luego de lo acontecido durante diciembre. Por otro lado, la segunda firma y la presentación del nuevo Plan de Seguridad Integral, buscó reforzar las relaciones entre dos jurisdicciones estatales como con la ciudadanía, mostrar la inversión de ciertos recursos económicos y humanos, así como la puesta en escena de que algo se está haciendo por la seguridad de Córdoba. Una alternativa hubiese sido firmar las actas en el despacho del secretario o en la oficina principal del Gobernador, o de la Jefatura con la presencia de algunos vecinos, o sólo entre funcionarios. Por el contrario, el objetivo fue exhibir y celebrar la firma del convenio, no sólo para los y las presentes sino para la audiencia mediática.

Estos rituales seculares, que dan forma a la vida política, presentan al estado como una entidad eterna, natural, necesaria y transparente, cuya función es otorgar respuestas y soluciones a los grupos vulnerables. Las respuestas que son elaboradas, en este caso para combatir a la inseguridad y al narcotráfico, en proyectos legislativos y gubernamentales que, si bien pueden asumir una perspectiva multidimensional del problema, esto puede o no traducirse en la incorporación de políticas sociales como elementos de la política de seguridad. Como vimos en el análisis del primer acto, las intervenciones de Diego y del comisario -ambos funcionarios del gobierno y a cargo de instituciones estatales- coinciden al referirse al estado como entidad abstracta cuya capacidad racional concretará las soluciones. Si bien ambos proponen una intervención estatal a través de la consolidación de un esquema policial más democrático y cercano al ciudadano, puede observarse en sus discursos una construcción 
diferenciada de esas cercanías/lejanías. El rango entre éstas depende, una vez más, de sus esquemas morales y sociales, que contribuyen a definir el marco fundamental sobre el que se articulan ciertos juicios morales. La metonimia de moto y chorro es un claro ejemplo de ello. Hasta el momento utilicé indistintamente las categorías vecino y ciudadano. Sin embargo, en esta instancia considero importante señalar que desde el discurso gubernamental no refieren a lo mismo. En los actos analizados puede reconocerse un uso diferencial de estas categorías. En la presentación formal de ambos actos se recurre al uso de la categoría ciudadano, mientras que vecino/a es más bien empleada estratégicamente por el intendente y el gobernador, así como por Rubén, para interpelar a una audiencia desde un lugar cercano y compartido. Ponderar el uso de la categoría vecino/a por sobre otras, llama la atención sobre la gestión simbólica de determinados sentidos de comunidad nacional-provincial. Este uso diferencial puede observarse, asimismo, en los programas gubernamentales y marcos normativos relacionados, donde la categoría ciudadano y ciudadanía es construida desde un lugar genérico y totalizante, pero con cierta carga política. En cambio, la categoría vecina/o, en el marco del Consejo barrial donde realicé trabajo de campo, quedaba circunscripta a un uso cotidiano por los funcionarios públicos como parte de una estrategia discursiva que buscaba adscribir a ese ciudadano genérico a un territorio, pero también a ciertos recursos simbólicos y económicos. En la misma línea, el/la vecino/a era construida como una categoría neutra, sin contenido político, que por momentos aparecía asociada a la categoría de víctima. En primer lugar esta asociación era observada en las reuniones del Consejo cuando los vecinos/as intervenían narrando diferentes situaciones, problemas o incertidumbres. Algunas relacionadas con hechos de inseguridad -propios o de terceros- donde había existido, además, un padecimiento de la violencia inscripto en el cuerpo (golpes, empujones, zamarreadas, etc.) o en la propiedad privada. En segundo lugar, aquellos reclamos proclamados a un estado ausente en el cumplimiento de las garantías y derechos ciudadanos (educación, salud, servicios públicos); como aquellos referidos a la Institución Policial en el control urbano de los sujetos y territorios. La definición y tensión entre una y otra, forma parte de los interrogantes que trato de examinar en mi tesis de licenciatura.

La gestión de la (in)seguridad se pone de manifiesto a través de estas prácticas políticas de gobierno -así como en otras prácticas gubernamentales- cuyo interés primario es mostrar al público y a la ciudadanía que se invierte en el problema, legitimando la intervención de ciertos agentes (técnicos, arquitectos, especialistas) como la necesaria modificación de las políticas públicas en vigencia. En este contexto, y retomando una pregunta de Blázquez (2014): 
¿Cuáles son las metáforas movilizadas o procedimientos lingüísticos que envuelven a la política securitaria como símbolos y parafernalia de la legitimidad política?

Al tratar de desentrañar toda esa parafernalia de conductas y relaciones que se construyen y disputan en estos actos gubernamentales, podemos observar, recuperando a Schechner (2000) un encadenamiento de conductas integradas a una serie de acciones conjuntas. En primer lugar, si bien el momento de la firma es considerado como el momento central de la celebración -se supone que sin ella no habría acuerdo, además del hecho que da nombre al evento- es necesario asimismo que los funcionarios se expresen a favor del acuerdo, y a través de ello validar un conjunto de posiciones, relaciones y jerarquías. Así, los distintos oradores reconstruyeron desde lugares disímiles su relación con el problema de la (in)seguridad, su relación con el estado y con los destinatarios de estos proyectos securitarios. No obstante, es posible identificar un hilo conductor en tales intervenciones donde el problema de la seguridad se circunscribe al mal comportamiento o costumbres de determinados sujetos y sectores sociales. En segundo lugar, los dos anfiteatros estaban repletos de un público que de alguna manera se sentía atraído por el problema securitario; y, algunos de ellos, invitados y agasajados especialmente: miembros de las Juntas de Participación Ciudadana, y de los Consejos barriales. A través de su presencia, el gobierno de provincia buscó incorporarlos dentro del esquema institucional, validando tras esta serie de convenios ( $\mathrm{y}$ otros que se firmaron posteriormente) su lugar en la cogestión securitaria (un lugar -como vimos- subsidiario a las agencias y agendas estatales). Para ello, fue clave la producción de una imagen de reconciliación y consenso social que les permitiera a los agentes estatales desvincularse de los hechos de diciembre -especialmente la policía- y de ciertas valorizaciones negativas hacia su profesión. El apelo a una construcción conjunta de la seguridad como problemática general que atraviesa la cotidianidad, como a imágenes desesperanzadoras y desoladoras frente a la delincuencia, son algunas de ellas.

No obstante, esta producción de consenso no necesariamente garantiza una igualdad de condiciones $\mathrm{u}$ oportunidades. El reclamo de los motoqueros tensiona el convenio gubernamental de "seguridad" firmado con los vecinos/as, al visibilizar las consecuencias que estas políticas persecutorias y de control vehicular adquieren para este grupo en particular. Por último, el uso de términos beligerantes como los vamos a ir a buscar, o vamos a darle batalla "un efecto de retórica que elude las problemáticas de la segregación y las desigualdades para focalizarse con exclusividad en los problemas de los desórdenes y las violencias, la cuestión social se transforma en una cuestión marcial" (Fassin, 2016: 70). 


\section{Notas}

(1) En el presente artículo usaré itálica para resaltar categorías nativas, entrevistas como diálogos informales que mantuve con mis interlocutores. Las citas bibliográficas y categorías teóricas serán introducidas a partir del uso de comillas dobles o párrafo aparte según su extensión, siguiendo el formato Normas APA (2016).

(2) Como primera advertencia debo señalar que tales escenas no serán reconstruidas en su totalidad. Esto se debe a la extensión de las mismas y al límite consignado. Asimismo, tal recorte analítico buscará recuperar aquellas cuestiones que considero interesantes para desentrañar en el siguiente trabajo.

(3) Los nombres utilizados son ficticios para preservar la identidad de mis interlocutores, salvo en aquellos casos de los funcionarios públicos que por su rango serían fácilmente identificables.

(4) Para conocer más en detalle tales hechos recomiendo un documental emitido por Canal 10 (Córdoba) Córdoba no duerme dirigido por Gabriela Cabus y producido por Caleidoscopio.

(5) Motoquero o motero es una categoría social que hace referencia a una persona aficionada a la conducción de motocicletas y/o a la moto en sí misma. Podríamos establecer un primer nivel de diferenciación con los motociclistas, individuos que conduce una motocicleta sea por trabajo, necesidad de transporte, afición. No obstante, tales definiciones deber ser discutidas.

(6) Tal es el sobrenombre que recibió Ley Nro. 10138: patentamiento de cascos de motos. La normativa aprobada por la Legislatura de Córdoba en marzo de 2013 obliga a los motociclistas a colocar una calcomanía con la patente del rodado sobre el casco. Actualmente las manifestaciones y reclamos continúan a nivel provincial. Sin embargo, la posible reforma de determinados puntos de la Ley de Tránsito vigente encabezada por la actual Ministra de Seguridad Patricia Bullrich ha despertado reclamos en varias provincias (Buenos Aires; Mendoza, Tucumán, entre otras). Los puntos fuertes de la reforma apuntan a restringir el uso y circulación de motos como parte de un plan integral contra el delito. La relación causal delito-delincuentes y motos-motociclistas es presentada, por el gobierno y por los medios, como principal hipótesis de inseguridad. Asimismo, la reforma busca prohibir la circulación de dos personas en determinadas zonas y franjas horarias, siendo los responsables de seguridad de cada provincia los encargados de diseñar sistemas para que se cumplan estas cuestiones. Ver Día a Día, 06/03/2017: http://diaadia.viapais.com.ar/cordoba/ley-antimotos-patente-en-el-casco-chaleco-y-prohibicion-de-andar-de-dos

(7) El análisis de dicho mapa según el gobierno provincial arroja los siguientes datos: de 119 cuadrantes 40 están en rojo, es decir el $20 \%$ del mapa corresponde a una zona crítica, lo que equivale a 200 barrios que se encuentran en un mayor nivel de vulnerabilidad. Además, 25 barrios que fueron señalados con color rojo coinciden con zonas puntuales que el último jefe de la FPA (Fuerza Policial Antinarcotráfico) habría señalado como zonas "calientes" de ventas de droga y narcomenudeo.

(8) El conflicto entre De la Sota y Cristina Fernández de Kirchner, en aquel entonces gobernador de la provincia y presidente de la Nación respectivamente, era conocido. Más allá de las diferencias políticas entre ambos, la tensión se debió a cuestiones vinculadas con la repartición de fondos. Parte de la campaña política y mediática del actual presidente Macri en relación a la provincia de Córdoba se relacionó con esta situación y su propuesta incluía el mejoramiento de las relaciones económicas entre ambos gobiernos. No obstante, es un conflicto que ha emergido en la actualidad, donde el clima electoral dicta una agenda tironeada de ambos lados.

(9) Considero interesante señalar tales diferencias en la intensidad de voz, ya que nos permiten estar atentos y diferenciar momentos "calientes" de momentos "fríos", así como reflexionar sobre el uso distinguido y estratégicos de tales recursos en los actos políticos y gubernamentales. Asimismo, supone un desafío metodológico y analítico de 
mayor envergadura, ya que encuentro complejo la traducción de tales fonemas y/o intensidades al lenguaje escrito. Lo resalto como una cuestión a tener en cuenta al momento de analizar los discursos gubernamentales, así como cualquier tipo de discursos sociales.

\section{Bibliografía}

Abrams, P. (1977). Notas sobre la dificultad de estudiar el Estado. Journal of Historical Sociology, 1(1), pp. 58-89.

Annunziata, R. (2013). Democratizar la ciudad. Los presupuestos participativos en Rosario y Morón. Revista Nueva Sociedad, 243, enero-febrero, pp. 119-130.

Blázquez, G. (2014). Los actos escolares. El discurso nacionalizante en la vida escolar. Buenos Aires: Miño y Dávila Editores.

Elias, N. (2016). El proceso de la civilización. Investigaciones sociogenéticas y psicogenéticas. México: Fondo de Cultura Económica.

Fassin, L. (2016). La razón humanitaria. Una historia moral del tiempo presente. Ciudad Autónoma de Buenos Aires: Prometeo Libros.

Foucault, M. (2006). Seguridad, territorio y población: Curso en el College de France: 19771978. Buenos Aires: Fondo de Cultura Económica.

Foucault, M. (1988). El sujeto y el poder. Revista Mexicana de Sociología, 50(3), pp. 3-20.

Geertz, C. (1999). Definición política: las fuentes del orden y Bali y la teoría política. En Geertz, C. Negara. El estado-teatro en el Bali del siglo XIX. Madrid: Paidós Ibérica.

Kessler, G. (2011). El sentimiento de inseguridad. Sociología del temor al delito. Buenos Aires: Siglo Veintiuno Editores.

Lenoir, R. (1993). Objeto sociológico y problema social. En Champagne, P. (Ed.). Iniciación a la práctica sociológica (pp.57-102). México: Siglo Veintiuno Editores.

Schechner, R. (2000). Performance. Teoría y prácticas interculturales. Universidad de Buenos Aires, Secretaría de Extensión Universitaria: Centro Cultural Ricardo Rojas.

Sousa Lima, A. C. y Castro, J. P. (2008). Política(s) Pública(s). En Pinho, O. y Sansone, L. (Ed.). Raça novas perspectivas antropológicas (2da edicao) (pp. 351-391). Salvador: ABAEDUFBA. 